\title{
Equal critical care consideration for both immunocompromised and immunocompetent patients during the COVID-19 surge
}

\section{Cynthia DENIS}

Hopitaux universitaires de Strasbourg

Mathieu BALDACINI

Hopitaux universitaires de Strasbourg

Maleka SCHENCK

Hopitaux universitaires de Strasbourg

Thierry ARTZNER

Hopitaux universitaires de Strasbourg

Yoann GRIMAUD

Hopitaux universitaires de Strasbourg

Thierry LAVIGNE

Hopitaux universitaires de Strasbourg

Ferhat MEZIANI

Hopitaux universitaires de Strasbourg

Vincent CASTELAIN

Hopitaux universitaires de Strasbourg

Raphael CLERE-JEHL

Hopitaux universitaires de Strasbourg

Francis SCHNEIDER

Hopitaux universitaires de Strasbourg

Guillaume MOREL ( $\nabla$ guillaume.morel@chru-strasbourg.fr)

Hopitaux universitaires de Strasbourg https://orcid.org/0000-0002-8838-2431

\section{Research}

Keywords: COVID-19, critical-care, ethics, human, immuno-compromised, immuno-competent, logistics, management, outcome

Posted Date: August 26th, 2020

DOI: https://doi.org/10.21203/rs.3.rs-57911/v1 
License: (c) (i) This work is licensed under a Creative Commons Attribution 4.0 International License. Read Full License 


\section{Abstract}

Background: SARS-CoV-2 disease (COVID) affects all sections of the community, but some people contract the disease in a form requiring ICU admission. Immunocompromised patients (ICP) figure among the fragile patients whose access to critical care may be denied in the event of ICU bedshortage. Our aims were: 1) to describe our management experience in seeking to assure equal criticalcare consideration for both ICP and immuno-competent patients during the COVID surge, 2) to assess how successful this would be in terms of outcome for all patients, 3) to compare ICU stays of ICP, whether they survived or not, so as to detect possible prognostic factors.

Methods: We conducted a cohort study in medical ICUs of a university-affiliated hospital hit by an uncontrolled cluster of COVID. We compared the levels of activity before and during COVID: number of patients (whether COVID+ or COVID-, whether ICP or not); bed-occupancy and bed-availability; mortality rates and the need for sanitary evacuations analyzed to avoid triage decisions.

Results: During the pre-COVID period, 396 patients, including 9.3\% ICP, were admitted. During the COVID period, 547 patients, including 243 COVID + (of whom 24 ICP), were admitted: this required an 8 ICU bedextension (+14.5\% beds), a transfer of 69 immuno-competent COVID-patients to surgical ICU step-down beds, and the transfer of 22 immuno-competent COVID patients to distant hospitals. Despite sanitary evacuations, there was a daily average of 2 ICU-access refusals, the patients being taken in charge by step-down units. Health evacuations were decided on when the weekly number of COVID admissions doubled. No ICP was denied access to the ICU; no COVID- ICP was hospitalized during the first 9 weeks of the surge. 28 -day mortality was $41.6 \%$ in ICP versus $27.3 \%$ in immuno-competent patients $(p=0.021$, logrank test). With the exception of SAPSII and SOFA, no factor was different between clinical and ICU-stay characteristics among ICP, whether surviving or not.

Conclusion and Relevance: Equal critical-care consideration for both immuno-compromised and immunocompetent patients during the COVID-19 surge was possible with acceptable outcome. Sanitary doctrine and fine-tuned hospital logistics were mandatory both at local and national level to reach this goal.

\section{Introduction}

When the severe acute respiratory syndrome coronavirus 2 (SARS-CoV-2) emerged in China in 2019, even with the publicly-available data it was impossible to foresee precisely when it would hit our region in 2020 and to what extent the disease would require intensive care unit (ICU) admission. Although SARS-CoV-2 was not reported as being "a great killer" (1), it rapidly became obvious through estimates of the population at increased risk that COVID-19 would eventually lead to a high number of patients requiring hospital stays (2). Patients with the highest risk of death are probably those with well-documented risk factors (3) or with immune suppression. Given that immuno-compromised patients (ICP) represent a large number of patients predisposed to death on account of the weakness of their defense, ongoing 
organ failures and immune suppressive drugs as treatment $(4,5,6,7)$, their outcome during SARS-CoV-2 was a matter of concern.

The SARS-CoV-2 epidemic affected eastern France early on, with an uncontrolled cluster arising near our hospital in March. In our referral centre for cancer, organ transplantation and immune diseases, critically ill ICP have been treated for decades with the same consideration as other critically ill patients. Providing equal care support for COVID-19 (COVID+) and non-COVID-19 patients (COVID-) was a paramount element in defining care principles for coping with the likely surge of COVID+ patients, as was making intensive care available to everyone in need (8). Despite the threat of seeing our ICUs overburdened, we decided to admit all critically ill ICP as previously, whether with SARS-CoV-2 infection or not. This raised both ethical and logistical issues. We report clinical characteristics and outcome of the ICP cohort of COVID+ patients whom we were able to treat despite the risk of bed-saturation.

\section{Definitions, Patients And Methods}

\section{Settings and periods of observation}

The baseline ICU capacity of our 2,636-bed third-level university hospital includes 101 beds, of which 80 are staffed in the absence of epidemic or catastrophe. This study was conducted within the medical part of the ICU department, with 55 staffed beds located on 2 sites and a 20-year average occupancy of $95 \%$ (2,000 admissions per year). Over the last 2 decades, the overall average ICU-mortality has been between $17.2 \%$ and $25.1 \%$, with an average SAPS II between 48 and 65 and a mean ICU-length of stay ranging between 7 and 11 days.

We defined two periods of study: a pre-COVID period from 1 January to 29 February, and a COVID period from the first COVID+ admission (week 10, 3 March) until 31 May when no new COVID patient was admitted.

All patients received an information notice and the study was approved by the local institutional review board.

\section{ICU admission policy}

In the pre-COVID period, referral specialists proposed admission of patients to the ICU. In view of the experience elsewhere, a surge of immuno-competent COVID patients was expected. ICU access for ICP was therefore immediately on the agenda, although no formal deliberation was started between intensivists and referral-specialists to define restricted ICU admission for ICP. Early in 2020 national medical and administrative recommendations were issued by legal authorities as well as scientific societies (9-14) to guide medical decisions on patient transfer to ICUs. We decided, in consultation with the institutional administrative crisis unit (IACU, see below), that for ICP patients as for every other patient admission to the ICU had to be conditioned by a constant concern to provide equal consideration regarding critical care. 
Immuno-compromised patients (ICP)

Patients displaying one of the following conditions were considered as "immuno-compromised": Human Immunodeficiency Virus disease; chemotherapy-induced aplasia; immune suppressive treatment for solid organ transplantation or for connective tissue diseases. All other patients were considered as having no serious immune defect.

\section{Logistics organization \& institutional administrative crisis unit (IACU)}

Generally, the running and functioning of ICUs remain in the hands of physicians. During a catastrophe, the guidance responsibility shifts to an institutional administrative crisis unit (IACU) headed by the chief administrative officer of the hospital who has daily meetings with an advisory board comprising representatives of front-line physicians and the main elected representatives of the hospital and the city. The IACU takes decisions for the hospital community in line with national health policy. Because no specific in-hospital organization had been planned for epidemics since the 1918 H1N1-pandemic, the IACU adopted new rules of functioning. It thus assumed charge for coordinating a balance in COVID admissions between our hospital and neighboring public and private hospitals, as well as for coordinating critical care with the "Grand Est" regional administration (5 555000 inhabitants, 57441 $\mathrm{km}^{2}$ ), which was responsible for extending bed-availability and, if necessary, health evacuations towards distant hospitals in cooperation with national health authorities and the Foreign Ministry.

\section{Statistics}

Continuous variables were expressed as medians with interquartile ranges (IQR). Categorical variables were described using counts and percentages. Comparisons were performed using the Fisher exact-test or the Mann-Whitney test, as appropriate. Survival curves were established with the Kaplan-Meier method and the difference between immuno-competent and immuno-compromised patients was analyzed with a log-rank test. Analyses were performed on R statistical software.

\section{Results}

\section{Beds \& staff modifications during the COVID period}

As indicated (Figure I, week 10), when the first COVID+ patients were admitted the 55 medical ICU-beds were already almost all occupied by non-COVID patients. Anticipating an overflow of COVID+ patients, the IACU immediately cancelled elective surgical and non-emergency procedures and expanded:

- the surgical ICU, whose capacity rose progressively from 46 to 147 ICU-beds (over 3 weeks), including ephemeral COVID-ICU beds in step-down units,

- the medical ICU department capacity immediately from 55 to 63 beds (+ $15.5 \%$, upper limit due to architectural constraint), 
so as to bring our institutional ICU-bed availability to a level $30 \%$ above the number of COVID+ patients treated by mechanical ventilation two weeks earlier in Lombardy, Italy (bed/inhabitants: $0.21 \%$ versus $0.15 \%)(8)$.

Anesthesiologists and intensive-care trained nurses were relocated to these facilities at a ratio of " 1 nurse for 2 beds". At national level, full lockdown of the population was decreed on 17 March (week 12). When, at week 19, the number of COVID admissions fell, the number of ICU beds was immediately reduced from 63 to 55 so as to reflect the level of occupancy (Figure 1).

\section{COVID-associated changes in the flow of admissions}

During the pre-COVID period (Figure I, left part) regular critical-care treatment was dispensed to 396 COVID- patients, including 37 ICP (9.3\%). During the 3-month COVID period (weeks 10 to 23) 547 patients were admitted, including 233 COVID+ patients, of whom 24 were ICP $(4.4 \%$ of admissions, $10.3 \%$ of COVID patients). There were thus $50 \%$ fewer ICP admissions than had been expected during the preCOVID period. These figures do not correspond to statistical differences in the provision of critical care to either category (number of monthly admissions of either category, proportion of ICP versus others). The transfer of immuno-competent COVID- patients to step-down beds commenced as soon as the first COVID+ patients arrived, so as to avoid the bed-saturation (week 11 to 12) that would have occurred within 3 days with our usual ICU length of stay for non-COVID patients. An immediate stop mechanism was also adopted for non-emergency procedures in anticipation of the possible post-operative saturation of surgical ICU beds. From weeks 12 to 16 , bed-saturation occurred despite these measures, although the number of patients who could not be admitted $(n=47)$ to our ICU but who were admitted to surgical ICUs freed by non-emergency procedures stopping was less than 2 patients per day. Strikingly, no COVID- ICP was proposed to our ICU from weeks 10 to 19 (Figure 1). Consequently, access to full critical care was not refused for any ICP.

From weeks 10 to 12, there was a rapid doubling in COVID+ admissions ( $+76.5 \%$ of basal level in week $11,+159 \%$ from basal level in week 12 ). Faced with this wholly unforeseen volume of patients, our IACU decided on health evacuation flights in week 12 (Figure 1) for two reasons: 1) because saturation of medical ICU beds had been reached not just in terms of bed-availability but, rather, on account of the presumed longer stay for COVID+ patients (in comparison with usual length of stay for COVID- patients); 2) because saturation was about to be reached in the institution as a whole (210 ICU-beds, with 208 occupied beds) despite bed-availability adjustments and because the effect of the lockdown on the number of admissions was not expected before week 14 (i.e.: week $12+15$ days). With the help of distant $(>1000 \mathrm{~km}$ ) hospitals in areas not yet badly affected by the SARS-CoV-2 (including hospitals in other countries), health flight evacuation of 22 immuno-competent COVID+ patients ( $10 \%$ of admitted COVID+ patients) was resorted to from weeks 13 to 15. As noted (Figure I, from week 15), a tangible decrease in COVID+ admissions occurred. Bed-availability therefore increased rapidly, as indicated by the difference between bed-occupancy and bed-availability. 
The national lockdown ended on week 20. From week 23 onwards, the COVID episode could be considered as finished in our ICU: COVID+ patients surviving abroad were then progressively repatriated.

\section{Characteristics of ICP with COVID}

Clinical characteristics and ICU-stay data of the ICP are reported in Table 1. Twelve (50\%) patients had a history of active cancer in the last five years (see histological types below Table 1). One patient had had two different cancers, without genetic link. Three of the oncology patients also had a history of hematological malignancy: one had hyper eosinophilia with increased Immunoglobulin E, one had a history of marginal zone lymphoma and diffuse large B cell lymphoma, and one had a multiple myeloma associated with lambda Immunoglobulin A. Eight patients had a history of hematological malignancy, consisting in lymphoproliferative disorders in 6 of the 8 cases (75\%). Within the previous 3 months, 2 patients had undergone autologous stem-cell transplantation (zero allogenic bone-marrow transplantation). Finally, 4 patients had had solid organ transplantation. No HIV patient was hospitalized during this period. Interestingly, 6 patients (25\%) displayed monoclonal gamma-pathology.

The severity of acute respiratory distress syndromes is illustrated by the presence of moderate to critical radiological infiltrates in most patients $(n=14 / 17(82 \%))$, low $\mathrm{PaO}_{2} / \mathrm{FiO}_{2}$ ratios, especially in the deceased group, and the recourse to mechanical ventilation in all patients but 2 . Non-invasive ventilation proved insufficient for most patients. One patient successfully underwent ECMO for 32 days.

Eleven patients (79\%) had a positive lupus anticoagulant. All but one received anticoagulant therapy, 11 (48\%) of them receiving a treatment dose: 3 patients developed venous thromboembolism and one patient, with newly diagnosed promyelocytic leukemia, died from a carotid artery occlusion.

Nine patients (37\%) developed healthcare-associated infection, chiefly ventilator-associated pneumonia (78\%). Only one patient had airway Aspergillus fumigatus colonization, without proof for invasive infection. Interestingly, $67 \%$ and $50 \%$ of the patients still had a positive PCR for SARS-CoV-2 swab sample at days 21 and 28 , respectively.

\section{Survival rates}

Figure II shows the actuarial survival of COVID patients, whether ICP or not. At day 28 , ICP had a significant decrease in survival as compared with other patients ( $41.7 \%$ versus $27.3 \%, p=0.021)$, but from 2 weeks after admission this difference remained stable until day $56(p=0.023$, not shown). No factor was significantly different between COVID+ ICP depending on whether they survived or not, with the exception of classic scores (SAPSII, SOFA) which were higher in non-survivors (Table I).

\section{Discussion}


This cohort study recounts our experience of COVID patients in a quasi-non-extendable medical-ICU in a large-sized referral hospital where the surge of COVID+ patients was expected with apprehension in the light of experience elsewhere $(8,15,16)$. Our concerns were concentrated on ethical issues linked to the possible need for triage of patients, as signaled by others (14) and in recommendations by health authorities and professional societies $(10,17,18,19)$. At first, the availability of ICU-beds for fragile patients such as ICP appeared unlikely. In fact, efficient, rapid and agile logistics, as well as the solidarity of distant hospitals, enabled us to ensure constant provision of equal critical care to ICP and other patients, with fair access to treatment for all.

Throughout the COVID-19 outbreak, we admitted a stable number of ICP with or without COVID. Although the 28-day mortality of immuno-competent patients with COVID over the period was as usual in our department, strikingly the death rate for ICP was twice as high. In the context of other respiratory infections such as influenza, ICP and immuno-competent patients have a similar mortality ratio $(20,21)$. It may thus be that ICP patients are especially impacted by the SARS-COV-2. Because an unusually-high number of patients of our cohort had lymphoid diseases, a lymphocyte defect may be involved in this mortality (22). However, the mortality rate of our COVID+ ICP lies in the range of those reported for ICP with ARDS of any origin (23) and of immuno-competent COVID+ patients of similar severity (24). It is noteworthy that ICP surviving at the day-15 mark in the ICU were still alive at day 56 in our cohort, which argues for extending full-code management to them as from that date. Long ICU-stays seem a feature of SARS-CoV-2 infection (25). In our experience COVID+ ICP patients were not ICU bed-blockers: their average length of ICU stay being as in our usual provision of critical care, there was no impact on our ICU admission policy during the outbreak.

Clinical and biological characteristics of ICP are comparable to the overall characteristics of patients with severe forms of SARS-COV-2 infection who require life-sustaining therapy $(3,25,26)$. Many developed ventilator-acquired pneumonia which negatively affected their prognosis. However, although running a high theoretical risk (21), our ICP did not develop invasive fungal infection, in contrast with reports concerning influenza epidemics (21). Another feature illustrated was the persistence of a prolonged positive viral load in these ICP for reasons that remain to be determined. Finally, as in immuno-competent patients $(27,28)$, thromboses were detected in ICP, with attendant difficulties as regards prescribing anticoagulants for those thrombocytopenic patients (29).

Despite warnings (8), we were surprised by the high number of COVID-19 patients arriving in our hospital. This is liable to occur anywhere, since the potential number of patients in an area depends not on bedavailability but on viral virulence, contagiousness, social distancing and on the control of clusters $(1,2)$. Nonetheless, our results indicate that equal critical-care consideration for all patients can be given during pandemics, although this is not advocated by all: some authors argue in favor on putting collective utility before individual care rather than deciding on a "first come, first served "basis (14). Management such as ours admittedly needs to be backed by a strong local sanitary policy as well as by financial and logistics support at national level. The capacity for providing intensive care to anyone in need was available for an additional reason: since some other hospitals in our region were not short-staffed because they had not 
yet been hit by the epidemic, it appeared a better solution for the population to provide transfer of patients towards those hospitals as soon as the surge increased beyond the maximum bed-expansion of both our department and the institution. With local bed-availability as the chosen priority, the principal issue became to ensure on-site competencies in critical care.

Our experience provides information on the extent to which a facility which is itself quasi-non-extendable can cope with the COVID problem over a short period of time. We immediately adapted our own bedcapacity to that of extended surgical ICU units of our environment when the number of COVID admission doubled over a week: this had to be accompanied by a simultaneous transfer of approximatively $10 \%$ of COVID-immuno-competent patients to step-down units. This latter figure took into account the expected average number of ICP whom we were used to treating before the pandemic. To prevent this expected number being exceeded, all non-emergency activities, including elective non-urgent surgery, were stopped so as to maintain bed-availability. In addition, somewhat unexpectedly, probably as a consequence of an effective lockdown of ICP, we did not admit any COVID- ICP this surge. Our data do not explain this specific point. One other possible explanation is that referral specialists may have triaged such patients in their own wards.

Our study has limitations. Similar results are achievable only in a rich and well ICU-equipped country. Also, they require solidarity between both hospital medical teams and populations from different areas. Neither can it be ignored that our institution has always provided strong support for care in the field of diseases associated with immune suppression, whereas another policy would probably have negatively impacted on ICP outcome. Finally, while covering only a sample of patients, the present study provides a detailed description of patients' clinical characteristics and outcome, in the context, on the whole, of the severest forms of COVID in immuno-competent patients. Larger descriptive studies are needed to help clinicians decide how to optimize the critical care of these ICP in the event of a second wave of COVID-19. Whether mortality risk factors can be identified to guide potential pre-admission triage remains to be determined.

\section{Conclusion}

ICP admitted for severe SARS-CoV-2 infection are likely to present a higher mortality rate in comparison with immuno-competent patients, but otherwise the characteristics of their stays are similar to those of immuno-competent COVID+ patients. Lymphoid-disease patients seem at the highest risk of developing severe forms. To achieve acceptable outcomes with constant and equal critical-care provision to all patients during a pandemic, both a sanitary policy and fine-tuned hospital logistics are mandatory at local and national levels, because solidarity is required to schedule health evacuations. In order to choose the best moment for evacuation, we suggest taking into account the following factors: bed-availability for ICU-patients before the epidemic and the potential for increasing in-hospital capacity; weekly percentage 
increase in new COVID+ admissions when the COVID surge is starting. In circumstances where ICUcapacity is no longer extendable, health evacuation represents the unique tool for avoiding on-site triage and related ethical issues until lockdown produces its effect on overwhelming admissions.

\section{Declarations}

\section{Ethics approval and consent to participate}

All patients received an information notice and the study was approved by the local institutional review board.

\section{Availability of data and materials}

The datasets analyzed during the current study are not publicly available but are available, from the corresponding author on reasonable request.

\section{Consent for publication}

The authors accepted the manuscript for publication.

\section{Competing interests}

The authors declare that they have no competing interests.

\section{Funding}

No funding was received for this work.

\section{Authors' contributions}

All authors contributed to data collection. CD, TA, MS, MB, YG and GM analyzed and interpreted the patient data. CD, TA, FS and GM were major contributors in writing the manuscript. All authors read and approved the final manuscript.

\section{References}

1. Phua J, Weng L, Ling L, Egi M, Lim C-M, Divatia JV, Shrestha BR, Arabi YM, Ng J, Gomersall CD, Nishimura M, Koh Y, Du B, for the Asian critical Clinical Trials Group. Intensive Care Management of Coronavirus Disease 2019 (COVID-19): Challenges and Recommendations. Lancet Respir Med 2020; 8:506-17. https://doi.org/10.1016/s2213-2600(20)30161-2.

2. Clark A, Jit M, Warren-Gash C, Guthrie B, HXWang H, Mercer SW, Sanderson C, McKee M, Troeger C, Ong KL, Checchi F, Perel P, Joseph S, Gibbs HP, Banergee A, Eggo RM, Global, regional, and national estimates of the population at increased risk of severe COVID-19 due to the underlying health conditions in 2020: a modelling study. The Lancet https://doi.org/10.1016/S2214-109X(20)30264-3 
3. Zhou F, Yu T, Du R, Fan G, Liu Y, Liu Z, Xiang J, Wang Y, Song B, Gu X, Guan L, Wei Y, Li H, Wu X, Xu J, Tu S, Zhang Y, Chen H, Cao B. Clinical course and risk factors for mortality of adult inpatients with COVID-19 in Wuhan, China: a retrospective cohort study. The lancet Vol 395 March 28, 2020. Doi: https://doi.org/10.1016/S0140-6736(20)30566-3.

4. Azoulay E, Mokart D, Pene F, Lambert J, Kouatchet A, Mayaux J, et al. Outcomes of critically ill patients with hematologic malignancies: prospective multicenter data from France and Belgium-a groupe de recherche respiratoire en reanimation onco-hematologique study. J Clin Oncol $31 ; 2013$ : 2810-2818

5. Harpaz R, Dahl RM, Dooling KL. Prevalence of immunosuppression among US adults; 2013. JAMA 2016; 316:2547-2548.

6. Kiehl MG, Beutel G, Böll B, Buchheidt D, Forkert R, Knöbl P, Kochanek M, Kroschinsky F, La Rosée P, Liebregts T, Lück C, Olgemoeller U, Schalk E, Shimabukura-Vornhagen A, Sperr WR, Staudinger T, Von Bergwelt Baildon M, Wohlfarth P, Zeremski V, Schellongowski P. Consensus statement for cancer patients requiring intensive care support. Annals of Hematology (2018) 97:1271-1282. https://doi.org/10.1007/s00277-018-3312-y.

7. Torres VBL, Vassalo J, Silva UV, Caruso P, Torelly AP, Silva E, Teles JM, et al. Outcomes in Critically III Patients With Cancer-Related Complications PLoS One. 2016; 11(10):e0164537. DOI: 1371/journal.pone.0164537

8. Cecconi M. Challenges and management in Italy and lessons learned. ICU management \& Practice 2020, I: 6-12

9. Information to support decision making: Information for patients, families and the public. COVID-19 rapid guideline: critical care (NG159) March 2020 (amended 12 June 2020) 1 of 3. NICE. https://www.nice.org.uk/guidance/ng159/resources/information-to-support-decision-making-pdf8708913901

10. Azoulay E, Beloucif S, Guidet B, Pateron D, Vivien B, and Le Dorze M. Admission decisions to intensive care units in the context of the major COVID-19 Paris-region area. Critical Care (2020) 24:293. https://doi.org/10.186/s13054-020-03021-2.

11. Azoulay E, Beloucif S, Guidet B, Pateron D, Vivien B, and Le Dorze M. Admission decisions to intensive care units in the context of the major COVID-19 Paris-region area. Critical Care (2020) 24:293. https://doi.org/10.186/s13054-020-03021-2.

12. Aziz S, Arabi YM, Alhazzani W, Evans L, Citerio G, Fischkoff K, Salluh J, Meyfroidt G, Alshamsi F, Oczkowski S, Azoulay E, Price A, burry L, Dzierba A, benintende A, Morgan G, Grasselli G, Rhodes A, Moller MH, Chu L, Schwedhelm S, Lowe JL, Christian MD. Managing ICU surge during the COVID-19 crisis: rapid guidelines. Intensive Care Med 2020. https://doi.org/10.1007/s00134-020-06092-5.

13. Biddison LD, Berkowitz KA, Courtnez B, et al. Ethical considerations: Care of the critically ill and injured an influenza pandemics and disasters: CHEST consensus statement. Chest 2014; 146: el 45S-el 55S. 
14. Vincent J-L and Creteur J. Ethical aspects of the COVID-19 crisis: How to deal with an overwhelming shortage of acute beds. European Heart Journal (2020): Acute Cardiovascular Care 0(0) 1-5. https://doi.org/10.1177/2048872620922788.

15. Grasseli G, Pesenti A, Cecconi M. Critical Care utilization for the COVID-19 Outbreak in Lombardy, Italy: early Experience and Forecast During an Emergency response. JAMA 2020.

16. Grasselli G, Zangrillo A, Zanella A, et al. Baseline Characteristics and Outcomes of 1591 Patients Infected With SARS-CoV-2 Admitted to ICUSs of the Lombardy Region, Italy. JAMA 2020.

17. Lamblin A, de Montgolfier S. COVID-19 and ethical considerations: valuable decision-making tools from the leading medical societies in France. Anesthesia Critical Care \& Pain Medicine 2020.

18. Swiss Society of intensive care Medicine. Recommendations for the admission of patients with COVID-19 to intensive care and intermediate care units (ICUs and IMVUs). Swiss Medical Weekly Special article. 24 march 2020. https://doi.org/10.4414/smw.2020.20227.

19. Vergano M, Bertolini G, Giannini A, Gristina GR, Livigni S, Mistraletti G, Riccioni L and Petrini F. Clinical ethics recommendations for the allocation of intensive care treatments in exceptional, resource-limited circumstances: the Italian perspective during the COVID-19 epidemic. Critical Care (2020) 24:165. https://doi.org/10.1186/s13054-020-02891-w.

20. Martin-Loeches I, Lemiale V, Geoghegan P, McMahon MA, Pickkers P, Soares M, et al. Influenza and associated co-infections in critically ill immunosuppressed patients. Crit Care Lond Engl. 02 2019; 23:152.

21. Azoulay E, Mokart D, Kouatchet A, Demoule A, Lemiale V. Acute respiratory failure in immunocompromised adults. Lancet Respir Med. 2019; 7:173-

22. Malard F, Genthon A, Brissot E, van de Wyngaert Z, Marjanovic Z, Ikhlef S, et al. COVID-19 outcomes in patients with hematologic disease. Bone Marrow Transplant. 2020;1-

23. Cortegiani A, Madotto F, Gregoretti C, Bellani G, Laffe JG, Pham T, Van Haren F, Giarratano A, Antonelli M, Pesenti A, Grasselli G, LUNG SAFE investigators and the ESICM Trials Group. Immunocompromised patients with acute respiratory distress syndrome: secondary analysis of the LUNG SAFE database. Critical Care (2018) 22:157. https://doi.org/10.1186/s13054-018-2079-9.

24. RECOVERY trial. Low-cost dexamethasone reduces death by up to one third in hospitalized patients with severe respiratory complications of COVID-19. http://www.ox.ac.uk/news/2020-06-16-low-costdexamethasone-reduces-death-one-third-hospitalised-patients-severe.

25. Wu C, Chen X, Cai Y, et al. Risk Factors Associated With Acute Respiratory Distress Syndrome and Death in Patients With Coronavirus Disease 2019 Pneumonia in Wuhan, China. JAMA internal medicine

26. Wang D, Yin Y, Hu C, Liu X, Zhang X, Zhou S et al. Clinical Course and Outcome of 107 Patients Infected With the Novel Coronavirus, SARS-CoV-2, Discharged From Two Hospitals in Wuhan, China. Crit Care 2020 Apr 30; 24(1):188. doi: 10.1186/s13054-020-02895-6.

27. Helms J, Tacquard C, Severac F, Leonard-Lorant I, Ohana M, Delabranche X, et al. High risk of thrombosis in patients with severe SARS-CoV-2 infection: a multicenter prospective cohort study. 
Intensive Care Med. 2020; 1 -

28. Leonard-Lorant I, Delabranche X, Severac F, Helms J, Pauzet C, Collange O, et al. Acute Pulmonary Embolism in COVID-19 Patients on CT Angiography and Relationship to D-Dimer Levels. Radiology. 2020; 201561.

29. Baldacini M, Pop R, Sattler L, Mauvieux L, Bilger K, Gantzer J, Schneider F, Beaujeux R, Simand C, Herbrecht R. Concomitant haemorrhagic syndrome and recurrent extensive arterial thrombosis in a patient with COVID-19 and acute promyelocytic leukaemia. British Journal of Haematology (2020); 189, 1050-1063. https://doi.org/10.1111/bjh.16768.

\section{Tables}

Table 1 


\begin{tabular}{|c|c|c|c|c|c|}
\hline & \multicolumn{2}{|c|}{ Survivors } & \multicolumn{2}{|c|}{ Deceased } & \multirow{2}{*}{ p value } \\
\hline & $\mathrm{N}$. & $\underline{\text { Statistics }}$ & $\mathrm{N}$. & $\underline{\text { Statistics }}$ & \\
\hline \multicolumn{6}{|l|}{ General characteristics } \\
\hline Age (years). median (IQR) & 14 & $63.5(46.8-71)$ & 10 & $68.5(64.2-70)$ & 0.32 \\
\hline Male gender. \% & 7 & $50 \%$ & 6 & $60 \%$ & 0.70 \\
\hline Performans status $<2$ & & $71 \%$ & 7 & $70 \%$ & 1.0 \\
\hline Body mass index $(\mathrm{kg} / \mathrm{m} \rrbracket)$. median (IQR) & & $28(26-31.8)$ & & $27.5(24.5-34)$ & 0.95 \\
\hline \multicolumn{6}{|l|}{ Immunodeficiency causes } \\
\hline Solid organ cancer ${ }^{a}$ & 8 & $57 \%$ & 4 & $40 \%$ & 0.68 \\
\hline Hematological malignancy ${ }^{b}$ & 3 & $21 \%$ & & $50 \%$ & 0.2 \\
\hline Solid organ transplant recipient ${ }^{c}$ & 3 & $21 \%$ & 1 & $10 \%$ & 0.61 \\
\hline Auto immune disease & 0 & $0 \%$ & 0 & $0 \%$ & - \\
\hline HIV & 0 & $0 \%$ & 0 & $0 \%$ & - \\
\hline \multicolumn{6}{|l|}{ Medical comorbidities } \\
\hline Cardiovascular comorbidity & 7 & $50 \%$ & 5 & $50 \%$ & 1.0 \\
\hline Diabetes mellitus & 2 & $14 \%$ & 4 & $40 \%$ & 0.19 \\
\hline Chronic kidney failure & 3 & $21 \%$ & 3 & $30 \%$ & 0.67 \\
\hline \multicolumn{6}{|l|}{ Clinical features } \\
\hline Admission temperature $\left({ }^{\circ} \mathrm{C}\right)$ & 14 & $37.9(36.9-38.4)$ & 10 & $38.2(37.4-39.1)$ & 0.44 \\
\hline Respiratory frequency (per minute) & 14 & $28(26-35)$ & 10 & $32(25-35)$ & 0.97 \\
\hline Days between first symptoms and intubation. median (IQR) & 14 & $9.5(7.8-11)$ & 10 & $8.5(5.3-14)$ & 0.94 \\
\hline $\mathrm{PaO}_{2} / \mathrm{FiO}_{2}(\mathrm{~mm} \mathrm{Hg})$ & 14 & $105(82-117)$ & 10 & $74(53-106)$ & 0.17 \\
\hline Prognostic scores at admission & & & & & \\
\hline
\end{tabular}




\begin{tabular}{|c|c|c|c|c|c|}
\hline SOFA. median (IQR) & 14 & $5(4-7)$ & 10 & $11(8-12)$ & 0.01 \\
\hline SAPS II. median (IQR) & 14 & $41(33-47)$ & 10 & $70(63-75)$ & 0.005 \\
\hline \multicolumn{6}{|l|}{ Organ support in ICU } \\
\hline Optiflow ${ }^{\circledR}$ ventilation before intubation $\%$ & 2 & 14 & 5 & 50 & 0.09 \\
\hline Mechanical ventilation (\%) & 12 & 86 & 10 & 100 & 0.49 \\
\hline Mechanical ventilation: days. median (IQR) & 12 & $9(7-21)$ & 10 & $9(4-10)$ & 0.19 \\
\hline Neuromuscular blockade (\%) & 7 & 50 & 8 & 80 & 0.21 \\
\hline Inhaled nitric oxide (\%) & 5 & 36 & 3 & 30 & 1.0 \\
\hline Prone positioning (\%) & 5 & 36 & 5 & 50 & 0.68 \\
\hline ECMO (\%) & 1 & 7 & 0 & 0 & 1.0 \\
\hline Vasopressors (\%) & 10 & 71 & 9 & 90 & 0.36 \\
\hline Vasopressors days. median (IQR) & 10 & $4(2-7)$ & 19 & $7(5-7)$ & 0.30 \\
\hline Renal-replacement therapy (\%) & 4 & 29 & 4 & 40 & 0.67 \\
\hline \multicolumn{6}{|l|}{ Biological parameters at ICU admission } \\
\hline Hemoglobin (g/dL). median (IQR) & 14 & $10.8(9.7-12.8)$ & 10 & $11.5(9.5-13.3)$ & 0.89 \\
\hline Leukocytes $\left(.10^{9} / \mathrm{L}\right)$. median (IQR) & 14 & $6.0(5.2-7.1)$ & 10 & $6.6(5.4-8.7)$ & 0.97 \\
\hline Lymphocytes (g/dL). median (IQR) & 14 & $0.4(0.2-0.7)$ & 10 & $0.6(0.3-2)$ & 0.17 \\
\hline Platelets $\left(.10^{9} / \mathrm{L}\right)$. median (IQR) & 14 & $195(57-260)$ & 10 & $144(88-182)$ & 0.63 \\
\hline Creatinin $(\mu \mathrm{mol} / \mathrm{L})$. median (IQR) & 14 & $81(70-148)$ & 10 & $69(61-102)$ & 0.84 \\
\hline C-Reactive Protein (mg/L). median (IQR) & 14 & $128(48-225)$ & 10 & $113(60-170)$ & 0.71 \\
\hline Procalcitonin ( $\mu \mathrm{g} / \mathrm{L}$ ). median (IQR) & 14 & $0.4(0.25-0.78)$ & 10 & $0.47(0.21-1.08)$ & 0.86 \\
\hline Gamma Globulin (g/L). median (IQR) & 11 & $6.5(5.6-8.6)$ & 6 & $6(4-6.8)$ & 0.52 \\
\hline Albumin (g/L). median (IQR) & 14 & $25(23-35)$ & 10 & $32(25-33)$ & 0.28 \\
\hline D-dimers $(\mu \mathrm{g} / \mathrm{L})$. median (IQR) & 14 & $2475(1362-4540)$ & 10 & $2895(1160-3662)$ & 0.79 \\
\hline
\end{tabular}

Page 15/18 


\begin{tabular}{|c|c|c|c|c|c|}
\hline Fibrinogen (g/L). median (IQR) & 14 & $6.9(5.7-7.5)$ & 10 & $7.2(4.8-7.6)$ & 0.98 \\
\hline Positive lupus anticoagulant $(\mathrm{n}=14)$ & 8 & $80 \%$ & 3 & $75 \%$ & 1.0 \\
\hline Proteinuria (g/L) & 13 & $1.2(0.9-2.1)$ & 7 & $1.0(0.7-1.3)$ & 0.45 \\
\hline \multicolumn{6}{|l|}{ CT-Scan features $(n=17)$} \\
\hline Mild & 2 & $17 \%$ & 1 & $20 \%$ & 1.0 \\
\hline Moderate to severe & 8 & $67 \%$ & 2 & $40 \%$ & 0.59 \\
\hline Critical & 2 & $17 \%$ & 2 & $40 \%$ & 0.54 \\
\hline \multicolumn{6}{|c|}{ Airways positivity for COVID 19 (rT-PCR ) } \\
\hline Day $7(n=17)$ & 10 & $100 \%$ & 7 & $100 \%$ & 1.0 \\
\hline Day $14(n=8)$ & 6 & $86 \%$ & 1 & $100 \%$ & 1.0 \\
\hline Day $21(n=6)$ & 4 & $67 \%$ & 0 & $0 \%$ & 1.0 \\
\hline Day $28(n=4)$ & 2 & $50 \%$ & 0 & $0 \%$ & 1.0 \\
\hline \multicolumn{6}{|l|}{ Morbidity } \\
\hline ICU stay (days. median (IQR)) & 14 & $9(7-26)$ & 10 & $4(4-12)$ & 0.43 \\
\hline \multicolumn{6}{|l|}{ Death (cause) } \\
\hline Refractory hypoxia & $*$ & $*$ & 5 & $50 \%$ & \\
\hline Sepsis & $*$ & $*$ & 4 & $40 \%$ & \\
\hline Thrombosis & & $*$ & 1 & $10 \%$ & \\
\hline
\end{tabular}

Causes of immune deficiency:

a: Cancer patients $(n=12)$ : renal clear cell carcinoma $(n=2)$; pulmonary adenocarcinoma with ALK mutation $(n=1)$; rectal adenocarcinoma ( $\mathrm{n}=1)$; osteosarcoma $(\mathrm{n}=1)$; thymoma $(\mathrm{n}=1)$; Ewing sarcoma $(\mathrm{n}=1)$; prostate adenocarcinoma $(\mathrm{n}=1)$; vesical carcinoma $(\mathrm{n}=1)$; urothelial carcinoma $(\mathrm{n}=1)$; thyroid carcinoma $(n=1)$; endometrial carcinoma $(n=1)$; pancreatic adenocarcinoma $(n=1)$.

b: Patients with hematologic diseases $(n=8)$ : multiple myeloma $(n=2)$; marginal zone lymphoma $(n=2)$; mantle cell lymphoma ( $\mathrm{n}=1)$; IgA kappa type lympho-plasmacytic lymphoma $(\mathrm{n}=1)$; chronic myelo-monocytic leukemia $(\mathrm{n}=1)$; acute pro-myelocytic leukemia, $(\mathrm{n}=1)$. 


\section{Figures}

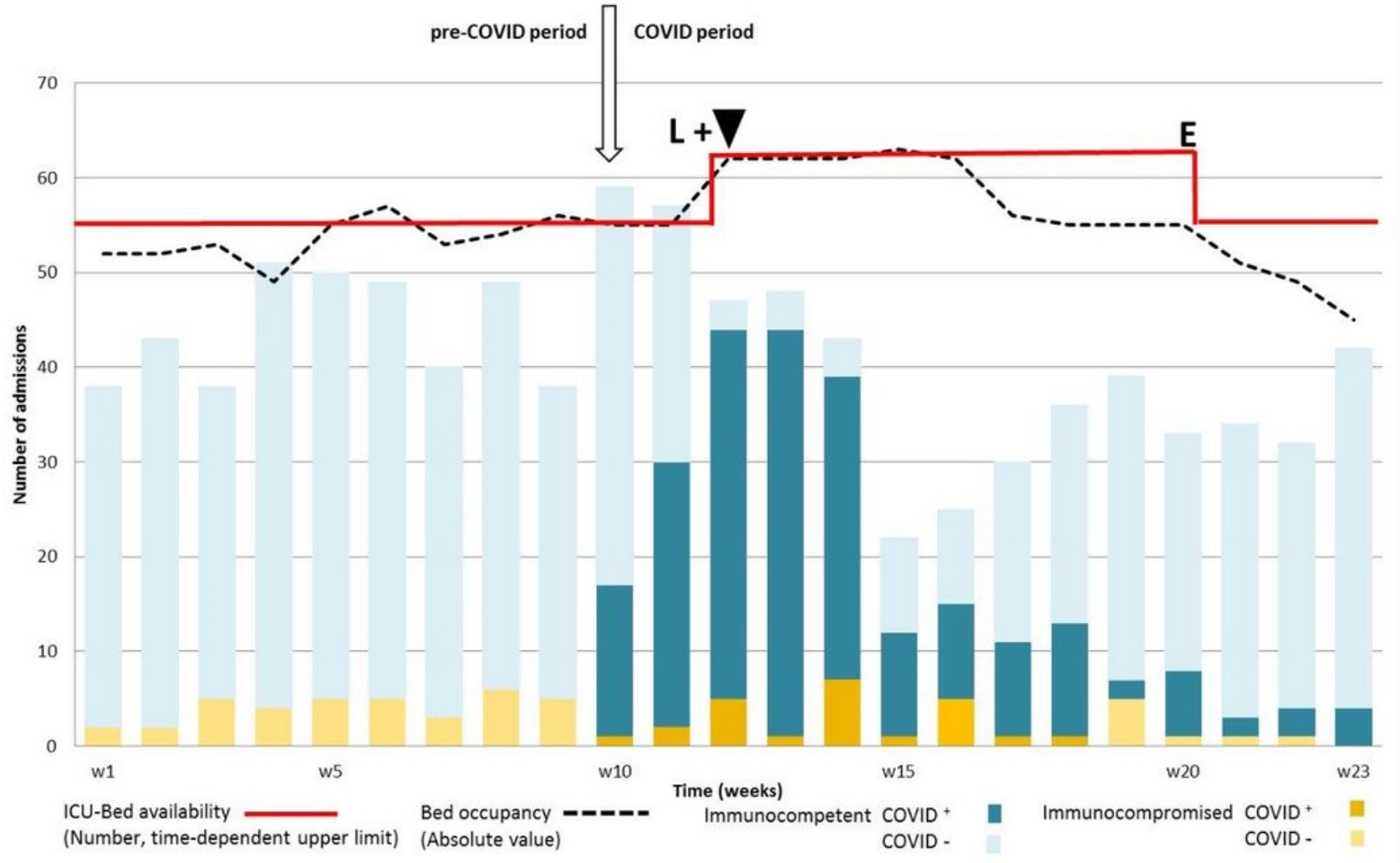

\section{Figure 1}

Weekly admissions of immunocompetent (blue) and immunocompromised (yellow) patients with (dark) or without (bright) SARS-CoV2 disease. From the very first COVID patient admission (white arrow, March 3rd) to the last one (week 23, May 30th), there was no significant difference in the average weekly number of immunocompromised patients admitted to our department when compared with the preCOVID period ( vs , $p=$ ). Throughout the COVID period, access for immunocompetent patients was maintained, with an average of 2 [range 0-17] admission refusal due to lack of place. The number of COVID+ patients increased by $76.5 \%$ from week 10 to week 11 , and by $158 \%$ from week 10 to week 12 . For this reason, local authorities decided to start health evacuation flights (black triangle) to avoid ICUbed saturation until the effect of the lockdown decided at national level $(L+$, week 12, March 17th until $E$, end of lockdown) which impacted tangibly the number of COVID admissions (week 15). The dashed black line indicates the maximal bed occupancy; the red line is the upper limit of bed availability before the COVID period $(n=55)$ and during the COVID period $(n=63)$. Please note that during the pre-COVID period, at two episodes, the availability of ICU-beds was already lower that the occupancy (week 6 and week 9) which indicates that in usual periods of care bed-availability is already at the limit of shortage. L: Beginning of lockdown E: End of lockdown 


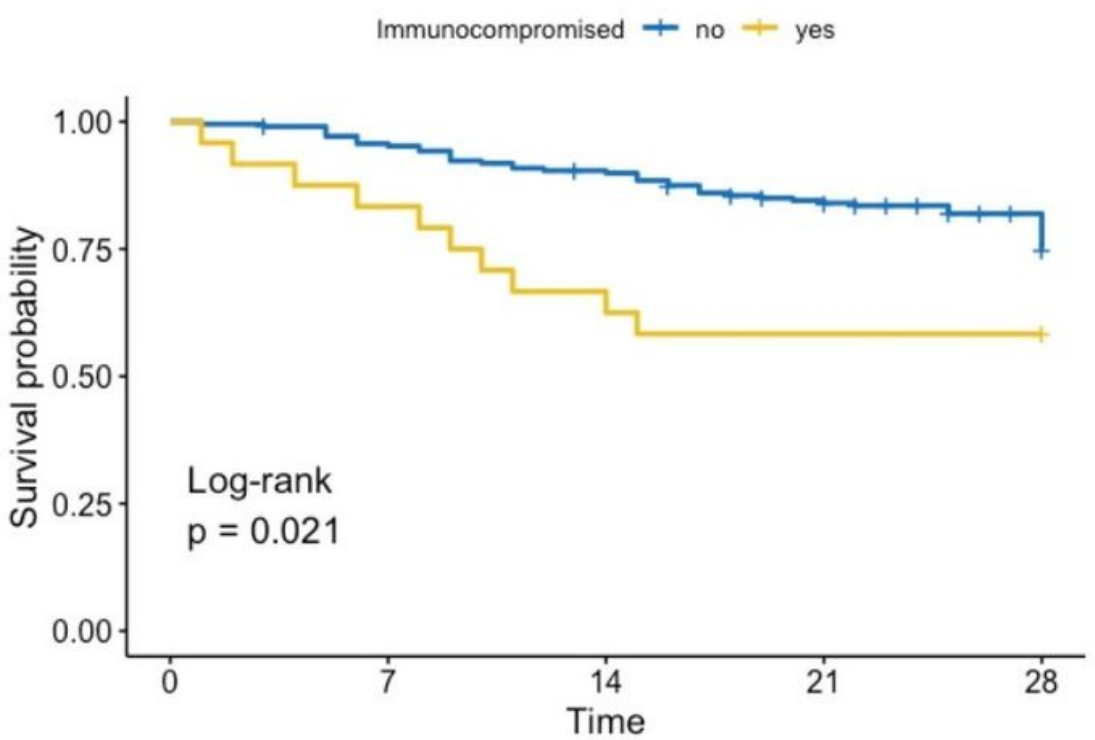

\section{Number at risk}

$\begin{array}{ccccc}=209 & 199 & 186 & 170 & 152 \\ =24 & 20 & 16 & 14 & 14\end{array}$

Cumulative number of events

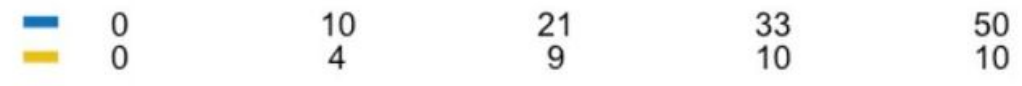

\section{Figure 2}

Overall survival of COVID+ patients Mortality of COVID+ ICP is significantly higher than mortality of COVID+ immunocompetent patients. The latter is in the range of mortality (all cause and all categories) of patients of the pre-COVID period (see Materials and methods section). 